\title{
PROPORTIONAL CHAMBERS FOR THE BARREL HADRON CALORIMETER OF THE L3 EXPERIMENT
}

\author{
L3 Collaboration \\ CERN, Geneva, Switzerland
}

\begin{abstract}
A. Arefiev', T. Azemoon ${ }^{2}$, U. Bachmann ${ }^{3}$, R.C. Ball' ${ }^{2}$, W.E. Böhlen ${ }^{3}$, M. Capell ${ }^{2}$, C. Chen $^{4}$, H.S. Chen ${ }^{4}$, M. Chumakov', Yu. Galaktionov', S. Goldfarb ${ }^{2}$, A. Gordeev', Yu. Gorodkov' ${ }^{1}$, E. Härdi ${ }^{3}$, H. Hofer ${ }^{5}$, B.N. Jin ${ }^{4}$, L.W. Jones ${ }^{2}$, Yu. Kamyshkov ${ }^{1}$, A. Klimentov' ${ }^{1}$, M. Koller ${ }^{3}$, V. Koutsenko ${ }^{1}$, V. Krylov', A. Kuhn ${ }^{3}$, A. Kunin', P. Lecomte ${ }^{5}$, P. LeCoultre ${ }^{5}$, H.T. Li ${ }^{3}$, X.G. Li ${ }^{4}$, X. Lou ${ }^{3}$, Y.S. Lu ${ }^{4}$, A. Malinin', V. Markizov', G.B. Mills', V. Morgunov' ${ }^{1}$, A. Nikitin', V. Plyaskin' ${ }^{1}$, V. Pojidaev ${ }^{1}$, B.P. Roe ${ }^{2}$, A. Savin ${ }^{1}$, P. Schär ${ }^{3}$, S. Shevchenko', V. Shevchenko ${ }^{1}$, K. Shmakov' ${ }^{1}$, V. Shoutko' ${ }^{1}$ E. Shumilov', B. Spiess ${ }^{3}$, X.W. Tang ${ }^{4}$, E. Tarkovsky ${ }^{1}$, V. Tchudakov', Samuel C.C. Ting ${ }^{6}$, K.L. Tung ${ }^{4}$, J. Ulbricht ${ }^{3}$, I. Vetlitsky ${ }^{1}$, I. Vorobiev' ${ }^{3}$, J.H. Wang ${ }^{4}$, R.J. Wu ${ }^{3}$, K.S. Yang ${ }^{4}$, S.Y. Zhang ${ }^{3}$ and H.L. Zhuang ${ }^{4}$
\end{abstract}

\begin{abstract}
The design and the mass production of the proportional wire chambers for the barrel part of the uranium-gas sampling hadron calorimeter of the L3 detector at the CERN Large Electron-Positron storage ring (LEP) are described. The chambers meet the specific requirements arising from the limited space available to the calorimeter, the radioactivity of uranium, and the physics criteria of good energy and position resolution for incident hadrons. The mass production techniques employed ensured that all of the 371,664 chamber cells have uniform response (with 5\% accuracy) to ionizing particles. Over 8000 chambers of the same design, in 53 different sizes, were manufactured and tested at the ITEP (Moscow), at the University of Michigan (Ann Arbor) and at the IHEP (Beijing). The assembly of the modules was done at the Paul Scherrer Institute (Würenlingen).
\end{abstract}

(Submitted to Nuclear Instruments and Methods in Physics Research)

1) Institute of Theoretical and Experimental Physics, Moscow, USSR.

2) University of Michigan, Ann Arbor, Mich., USA, supported by a grant from the US National Science Foundation.

3) Paul Scherrer Institute, Würenlingen, Switzerland.

4) Institute of High Energy Physics, Beijing, China.

5) Eidgenössische Technische Hochschule, Zurich, Switzerland.

6) Massachusetts Institute of Technology, Cambridge, Mass., USA. 


\section{INTRODUCTION}

The L3 experiment at the Large Electron-Positron storage ring (LEP) [1], currently being installed at CERN, is an all-purpose high-energy physics detector designed to measure various characteristics of reactions obtained in electron-positron collisions.

The detector (fig. 1), housed in a large-volume solenoid magnet, consists of a central particle track detector surrounded by an array of bismuth germanium oxide (BGO) electromagnetic shower counters. Hadron showers are detected both in the BGO counters and in a gas sampling hadron calorimeter. Penetrating muons enter a muon spectrometer consisting of three layers of precision drift chambers in the $0.5 \mathrm{~T}$ field. Experimentally, it is desired that only muons reach the muon spectrometer. Thus the hadron calorimeter has not only to measure the energy and direction of hadrons produced in the electron-positron interaction, but also to filter-out showering particles.

In designing the hadron calorimeter the following considerations were taken into account: The radial distance available to the hadron calorimeter is very limited. Therefore uranium, having a short nuclear interaction length $(\approx 11 \mathrm{~cm})$, is a natural choice for the absorber. After studies, proportional wire chambers were chosen as the shower sampling detectors. These are relatively easy to produce in large quantities. They are stable, reliable, and well understood, and can operate in a magnetic field. Moreover, a multiwire device offers the possibility of grouping the wires in a desired readout pattern. By arranging alternate wire planes orthogonally, accurate position resolution could be achieved.

The hadron calorimeter (fig. 2) consists of three major sub-assemblies: the central hadron barrel (HB), forward and backward end-caps (HC), and the muon filter (MF), which is the outside part of the barrel. Each sub-assembly has a modular structure. The modules of $\mathrm{HB}$ and $\mathrm{HC}$ consist of uranium absorber plates interleaved with proportional chambers. For structural and other reasons, the muon filter has a copper absorber. In this paper we describe the design of the proportional chambers of the barrel part of the L3 hadron calorimeter, the mass production procedure used for these chambers, and their testing during production.

\section{CHAMBER DESIGN}

A proportional chamber for the hadron calorimeter has to meet many requirements. Once assembled in a module (fig. 3), it may be inaccessible during the whole period of operation of the L3 experiment ( $>10$ years) - thus the chamber must be mechanically highly reliable and have sufficient radiation hardness. The dead space due to the gas distribution and to the wire supporting structure should be kept to a minimum so as to approach hermeticity. Owing to limited space, the chamber has to be as thin as possible, but at the same time it should keep the anode wires mechanically stable.

The tower structure of the modules and the orthogonal orientation of the anode wires of adjacent chambers required 53 different chamber sizes. In total, 7968 chambers had to be installed, the number of anode wires being 371,664 . The response of the chambers to ionizing particles should be uniform throughout the calorimeter.

For a chamber operating in the proportional mode, the uniformity of response depends critically on the mechanical precision of the chamber cells. Table 1 demonstrates that good uniformity is possible only when strict tolerances are met. Therefore the design was based on industrial-style production procedures, thus ensuring reproducibility. Because of the large number of chambers and wires required, it was necessary to make identical chambers at several locations (Moscow, Michigan, Beijing). This implied that the design should be simple to implement and that the tests should be designed to ensure uniformity. With this in mind, and on the basis of our experience in the operation of uranium-gas sampling calorimeters [2-6], the chamber design presented in figs. 4 and 5 was chosen.

The chamber body is a plane of rectangular brass tubes $(\mathrm{Cu}: \mathrm{Zn}=63: 37)$ with $0.3 \mathrm{~mm}$ thick walls and $5 \mathrm{~mm} \times 10 \mathrm{~mm}$ inner dimensions. The tubes are covered with $0.7 \mathrm{~mm}$ thick brass plates on 
each side; these serve both as a mechanical support and as a shield to diminish the flux of radioactivity through the chamber (figs. 6 and 7). The chamber is operated with the anode wires at ground and negative high voltage applied to the tubes. To prevent discharge to the neighbouring support structures, the shielding plates are grounded and are insulated from the tubes by means of polyester film. The anodes are gold-plated tungsten wires of $50 \mu \mathrm{m}$ diameter. The wires are crimped into gold-plated brass jacks, which are glued into polycarbonate (Makrolon) end-pieces. The gas is fed in parallel into the cells of the chamber through hard-PVC gas-manifold channels. The gas inlet and outlet plugs are situated on the two diagonal corners of the chamber. The gas flow varies by less than a factor of 2 in the different cells, which was found to be sufficient to maintain uniform gas gain and efficiency over the chamber cells.

In the $\mathrm{L} 3$ detector the natural radioactivity of the uranium absorber is the main cause of possible radioactive damage to the chambers. In tests for radiation resistance, the materials to be employed in the production, as well as several chamber prototypes were irradiated, using different radioactive sources (and at a reactor), and received doses which were orders of magnitude higher than what the chambers will receive in several years of continuous functioning in the uranium calorimeter.

When designing the chamber, various prototypes as well as the final chamber version were thoroughly tested with particle beams at both CERN and the ITEP [2-6].

\section{CHAMBER ASSEMBLY}

Table 2 outlines the steps used to build and test the chambers. During production, this required about 1 man-day per chamber. One of the first steps in the manufacturing of the chambers is the building of a chamber body, which is made from the tubes and shielding plates cut to proper dimensions. The tubes are cut to different lengths, from 350 up to $615 \mathrm{~mm}$, with a tolerance of ${ }_{-0.2}^{+0} \mathrm{~mm}$, a straightness of better than $0.03 \%$, and a twist of not more than $1 \% / \mathrm{m}$. These tolerances are critical for maintaining the desired chamber dimensions.

The edges of the tubes and shielding plates are deburred to prevent piercing or cutting of the Mylar foil insulating the tubes from the shielding plates. Before assembly, the tubes are chemically cleaned in a multistep procedure. As an example, the ITEP (Moscow) procedure is shown below:
a) ultrasonic bath in a detergent:
$10 \mathrm{~min}$;
b) a bath of $10 \%$ water solution of $\mathrm{NaOH}$ : $2 \mathrm{~min}$;
c) washing in running water: $2 \mathrm{~min}$;
d) a bath of $10 \%$ water solution of $\mathrm{H}_{2} \mathrm{SO}_{4}$ : 5 min;
e) a bath of $10 \%$ water solution of $\mathrm{K}_{2} \mathrm{Cr}_{2} \mathrm{O}_{7}: 4 \mathrm{~min}$;
f) washing in running water: $2 \mathrm{~min}$;
g) ultrasonic bath in Freon-113 + ethanol: $5 \mathrm{~min}$.

The cleaning removes grease and small pieces of brass and dirt from the tube walls. Similar methods achieved similar results at the other production sites.

The chamber bodies are assembled using a turntable equipped with a comb jig (fig. 8). Tubes of a length corresponding to a given type of chamber are inserted side by side on the teeth of a comb to form a plane, the HV connector having been soldered onto the wall of the outside tube (see figs. $4 \mathrm{a}$ and 8). The number of tubes depends on the chamber type. Two strips of copper tape coated with a conductive adhesive are smoothed down across the tubes to ensure tube-to-tube electrical contact. The shielding plates plus insulating Mylar foil are then placed on the sides of the plane formed by the tubes. The chamber body is held together using double-sided adhesive polyester (Mylar) sheets. The assembled bodies are put into an oven and heated to $120^{\circ} \mathrm{C}$.

The oven is equipped with a rubber diaphragm, and a vacuum is created so that the chamber body is flattened by atmospheric pressure. This procedure takes several hours. The vacuum pumping also removes the inevitable air bubbles between the layers of polyester foil, tubes, and plates. As a 
result of the oven treatment, the adhesive sets and the body becomes rigid and flat. To make sure that the Mylar foil between the tubes and shielding plates was not pierced when the chamber body was flattened in the oven, the insulation is tested for 30 min at $6 \mathrm{kV}$.

In the next step of chamber production, the end-pieces, with the brass jacks already in place, are glued to the chamber body. The end-pieces are built up of three or four shorter pieces. The plastic part of the end-piece is made in a high-precision mould. The specially designed gold-plated brass jacks are glued into the plastic end-piece with a cyanoacrylate adhesive (fig. 9). The brass jacks have a female signal connector and a slit into which the anode wire is fixed. The end-piece assures proper positioning of the wire in a chamber cell.

The wiring of the chamber is done on a special table equipped with pneumatic punches (fig. 10). The wire from a spool is pulled through each tube, then stretched using a weight of $240 \mathrm{~g}$, after which it is pneumatically crimped into the slits at both ends of the chamber. This procedure ensures a clean and reliable anchoring of the wires. So far, no wire has slipped out of the brass jack because of bad crimping. The mechanical tension of wires, as measured with an electromagnetic wire-tension meter, is uniform to within $\pm 10 \%$ (fig. 11).

At this point, with the chamber still open, every cell of the chamber is tested. This is done by the measurement of the 'dark' current drawn by each anode wire during a HV scan of the chamber in a nitrogen atmosphere [7]. The wires with a low discharge threshold (fig. 12) are then subjected to conditioning with a high voltage of inverse polarity. This procedure, when repeated several times, 'cures' most of the wires (fig. 13). The wires which show no improvement can be easily replaced at this stage of the production. On the average, $2 \%$ of the wires need to be replaced. The reason for the replacement (see table 3 ) is largely the poor surface quality of the wire, although the spools are carefully selected and the wire is cleaned by passing it through a sponge dampened with alcohol just before entering the tube.

The gluing of end-pieces to the chamber body and of the gas channels to the end-pieces (see fig. 5) is performed using gluing machines equipped with reservoirs with dispensing tips (fig. 14). The glue is forced out of the reservoir at a constant rate by compressed gas. At the ITEP, the dispenser was driven at constant speed along the end-piece by a motor, filling the slits and holes evenly. At the other two institutes, satisfactory results were obtained by hand. Two different glues were used: Black Max cyanoacrylate adhesive (Loctite 38031) and silicone rubber (Wacker Chemicals RTV-ME 622). When glued with silicone rubber, the parts of the chamber are primed with G790 primer to achieve the necessary bonding strength. The primer is also used to dilute the silicone rubber mixture to a lower viscosity. The chambers glued with Black Max had to be flushed with ammonia vapour to ensure full setting of the glue. In the final operation, the end-plugs are glued into the gas channel with a quick-setting cyanoacrylate adhesive.

The completely finished chambers are then subjected to four quality controls: visual inspection, dimension check, gas tightness, and HV insulation. The gas-tightness criterion is a pressure drop of less than $2 \mathrm{~mm}$ in $10 \mathrm{~min}$ at an overpressure of $100 \mathrm{~mm}$ of water. The $\mathrm{HV}$ insulation is tested at $4 \mathrm{kV}$ for $30 \mathrm{~min}$ in air.

As an example, table 4 summarizes the statistics of chamber faults encountered during production at the ITEP. Normally, a faulty chamber is disassembled to the stage where it can be repaired and then put back into the production chain. The final rejection rate is less than $4 \%$. Similar statistics were achieved at the other production sites.

\section{FINISHED CHAMBER TESTS}

The finished chambers are thoroughly checked under conditions similar to those in the hadron calorimeter module, i.e. in a uranium environment, with the working gas mixture $\operatorname{Ar}(80 \%)+\mathrm{CO}_{2}$ $(20 \%)]$, and at the working high voltage $(1.6 \mathrm{kV}-1.8 \mathrm{kV})$. 
The test procedure varied slightly in the different institutes. In the ITEP uranium spectrum test [8], the chamber is sandwiched between two uranium plates, and the amplified signals caused by the gamma radioactivity of uranium are sampled from each cell in sequence by a self-triggering ADC. The spectra obtained are then fitted to a high-statistics reference spectrum (fig. 15). The parameters of the fit reflect the gain and the efficiency of the chamber cell. Temperature and pressure variations are corrected for by normalization to the reference cell gain. Figure 16 shows the gain distribution for the different cells in one chamber. The uranium test set-up provided a quick (10 seconds per cell) and accurate $(\approx 3 \%$ r.m.s. $)$ way to test and calibrate the chambers.

During mass production at the ITEP the chambers are tested twice in the uranium test set-up, before and after 72 hours of 'ageing'. In the ageing facility the chambers are put between uranium plates and connected to a high voltage with the anodes at ground. During this test, the chambers are flushed with the working gas mixture, but are kept at $1.8 \mathrm{kV}$. At this voltage the gas amplification is an order of magnitude higher (fig. 17) than that under the expected operating conditions in the hadron calorimeter (where $1.6 \mathrm{kV}$ is used and the gas gain is about $10^{4}$ ).

At Michigan, after ageing in a uranium environment as at ITEP, the chambers are tested in a cosmic-ray 'telescope'. The pulse-height spectra from cosmic-ray muons are measured for each chamber cell.

At the IHEP the chambers are tested using cosmic rays, radioactive sources, and the uranium-spectrum procedure.

In the early stages of mass production, the long-term behaviour and ageing of the chambers was investigated at the ITEP, using cosmic rays [9]. This test measures the signals from cosmic muons traversing a stack of chambers interleaved with uranium plates.

Figure 18 illustrates the stability of the response of the chambers glued with the two different types of adhesive. The measurement was done using the uranium spectrum technique. From this and other measurements with strong radioactive sources and at even higher voltages it was concluded that, in the working conditions, the lifetime (defined as $10 \%$ gain loss) of produced chambers should be greater than 10 years.

The final control of all finished chambers is performed after their arrival at CERN. First the chambers are subjected to a number of acceptance tests, i.e. the dimensions, the HV insulation, and the gas tightness are checked. Then the chambers undergo the uranium-spectrum test described above. The uniformity of these chambers is illustrated in fig. 19, where the relative gas gain distribution for 225,000 wires $(5,000$ chambers) is plotted.

The assembly of the hadron calorimeter modules with the finished chambers and the uranium plates was done at the Paul Scherrer Institute (Switzerland).

\section{CONCLUSIONS}

The design for the proportional chambers for the barrel part of the uranium-gas sampling calorimeter of the L3 detector at LEP has been developed and implemented. By using planes formed by arrays of rectangular tubes, the design takes into account the following considerations: the specific requirements arising from the limited space available the calorimeter; the radioactivity of uranium; the need to produce large quantities of chambers of various dimensions in different laboratories (in total, over 7968 chambers, of the same design but in 53 different sizes, were built).

The technology developed for the mass production ensured that the gas amplification of all 371,664 cells was uniform with an accuracy of $5 \%$ (r.m.s.). 


\section{Acknowledgements}

We would like to express our gratitude to the many engineers and technicians for their impressive efforts during different stages of the chamber production - from the development of the chamber design and manufacturing technologies, through the building of the machinery and various test facilities, up to the successful completion of this work. In total, several hundred man-years were required. Special tribute goes to A. Alekhin, V. Bocharov, V. Dolgoshein, B. Gordeev, P. Kakouris, D. Kouba, V. Lioulevitch, N. Pankin, V. Plotnikov, H. Schick, V. Vinogradov, Z.J. Zhang, B.Q. Zhou and X. Zhou. We wish to thank Profesor Michael J. Longo, who was a major participant in the early design phases of the proportional chambers. 


\section{REFERENCES}

[1] The L3 technical proposal, CERN Report CERN/LEPC/83-5 (1983).

[2] F. Celletti et al., Nucl. Instrum. Methods A225 (1984) 493.

[3] A. Arefiev et al., Nucl. Instrum. Methods A245 (1986) 71.

[4] Yu. Galaktionov et al., Nucl. Instrum. Methods A251 (1986) 258.

[5] Yu. Kamyshkov et al., Nucl. Instrum. Methods A257 (1987) 125.

[6] C. Chen et al., L3Doc-562 (1988) submitted to Nucl. Instrum. Methods.

[7] S. Burov et al., preprint ITEP-191 (1987).

[8] S. Burov et al., A test and calibration set-up for mass-produced proportional chambers, to be submitted to Nucl. Instrum. Methods (1988). [A first version of this paper was circulated as preprint ITEP-204 (1987).]

[9] A. Arefiev et al., preprint ITEP-217 (1987). 
The gain variation of proportional chambers with a rectangular cell of inner dimensions $A=5 \mathrm{~mm}, B=10 \mathrm{~mm}$, and anode wire diameter $\mathrm{D}=50 \mu \mathrm{m}$

\begin{tabular}{|c|c|c|c|}
\hline $\begin{array}{c}\text { Varied } \\
\text { dimension of } \\
\text { the cell }\end{array}$ & $\begin{array}{c}\text { For } 5 \% \\
\text { variation } \\
\text { of gain }\end{array}$ & $\begin{array}{c}\text { For } 10 \% \\
\text { variation } \\
\text { of gain }\end{array}$ & $\begin{array}{c}\text { Tolerance } \\
(\mu \mathrm{m})\end{array}$ \\
\hline A & $\mu \mathrm{m}$ & $128 \mu \mathrm{m}$ & 50 \\
\hline B & $2.5 \mathrm{~mm}$ & & 70 \\
\hline $\mathrm{D}$ & $0.35 \mu \mathrm{m}$ & $0.7 \mu \mathrm{m}$ & 0.5 \\
\hline $\begin{array}{l}\text { Wire position } \\
\text { off centre: } \\
\text { for side } \mathrm{A}\end{array}$ & 190 & $380 \mu \mathrm{m}$ & 150 \\
\hline for side B & $750 \mu \mathrm{m}$ & $1.5 \mathrm{~mm}$ & 200 \\
\hline
\end{tabular}

Table 2

Overview of chamber production and testing

Materials preparation

Chamber body assembly

Dimension check

First high-voltage test

End-pieces with wire-holding device glued on

Wire stringing

Tension test

Dark-current test

(Wire replacement)

Gas manifold, plug inlet, and plug outlet glued on

Gas-leak test (and repair)

Second high-voltage test

Dimension check

Noise, ageing, and gain tests

Final inspection, packing, and shipment

Re-inspection and testing on delivery 
Table 3

The reasons for the replacement of wires after the dark-current test (in per cent of replaced wires)

Bad wire-holding

Kinked wire

Noisy wire
5.6

12.8

81.6

Table 4

Faults requiring recycling of the chambers during production (in per cent of tested chambers)

\begin{tabular}{|lr|}
\hline Kinked wire & 6.0 \\
Noisy wire & 19.3 \\
Insulation fault & 3.7 \\
Bad wire-holding & 3.7 \\
\hline No recycling & 67.3 \\
\hline
\end{tabular}




\section{Figure captions}

Fig. 1 General view of the $\mathrm{L} 3$ detector.

Fig. 2 L3 hadron calorimeter (HB: barrel part; HC: end-caps; MF = muon filter).

Fig. 3 Diagram of one of the nine rings of the sixteen modules which form the hadron calorimeter barrel.

Fig. 4 Barrel $\mathrm{HC}$ chamber.

Fig. 5 Cross-sectional view of barrel $\mathrm{HC}$ chamber.

Fig. 6 Uranium-induced pulse-height spectrum (dashed line) compared with cosmic-ray muons (full line).

Fig. 7 The dependence of the proportional chamber counting rate on the thickness of the copper sheet used as shielding for the uranium plate (measurement with single uranium plate). Zero thickness corresponds to the $0.3 \mathrm{~mm}$ of brass of the chamber wall. The accepted thickness of the copper is indicated.

Fig. 8 Body assembly turntable with combs.

Fig. 9 Plastic end-piece with brass jacks.

Fig. 10 Wire-crimping device.

Fig. 11 Distribution of wire tension; the acceptance limits are shown.

Fig. 12 Dependence of dark current on the voltage for different cells of a chamber. One line corresponds to one wire cell.

Fig. 13 Discharge threshold voltage distribution for chamber cells.

Fig. 14 Gluing machine.

Fig. 15 Reference spectrum of uranium-induced signals. One MIP is defined as the most probable amplitude of a minimum-ionizing particle.

Fig. 16 An example of uranium test data. Wire gain distribution.

Fig. 17 High-voltage dependence of the proportional gain in a chamber flushed with the working gas $\left[\operatorname{Ar}(80 \%)+\mathrm{CO}_{2}(20 \%)\right]$.

Fig. 18 Long-term ageing test in a uranium environment.

Fig. 19 The distribution of the relative gas gain for the wires. 


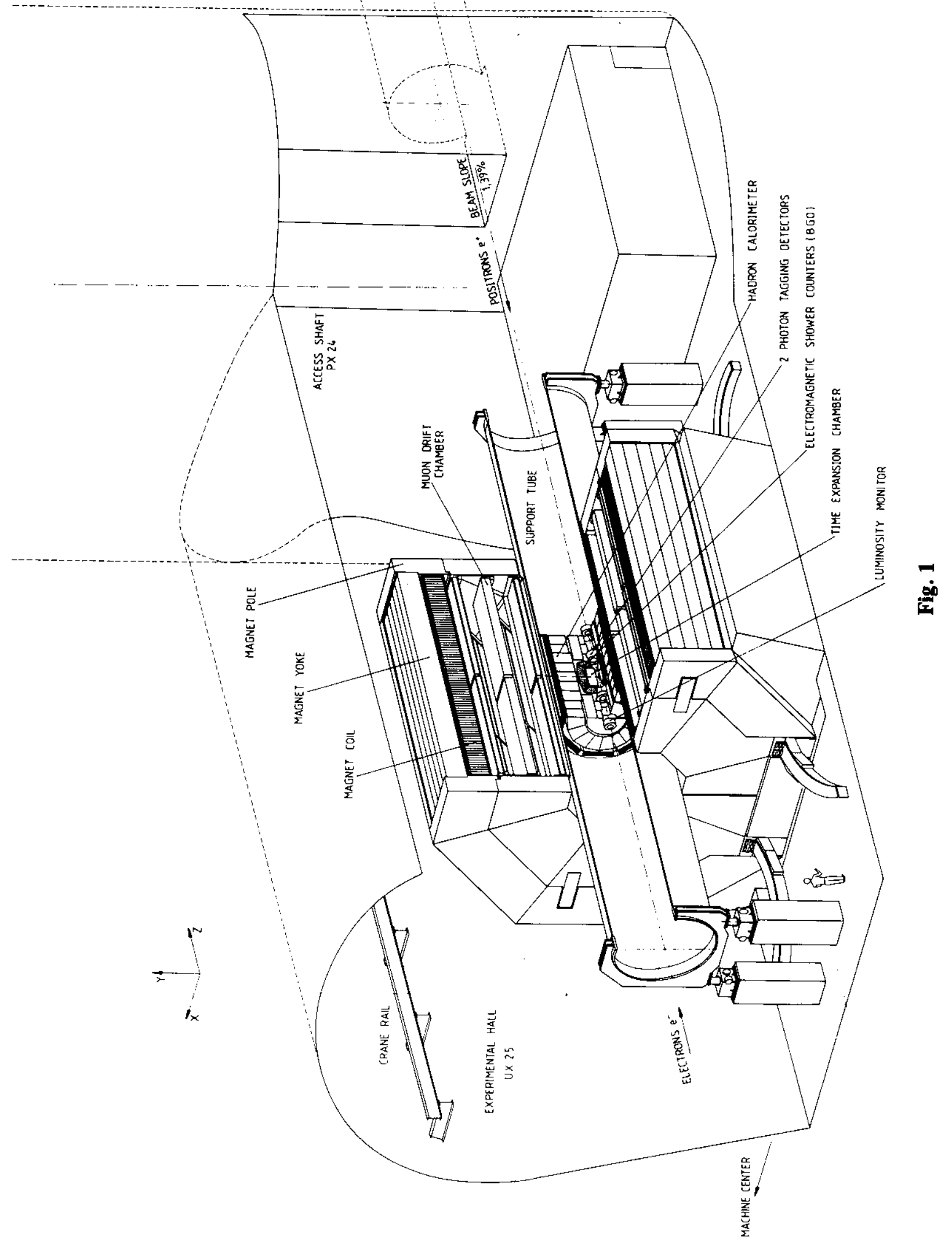




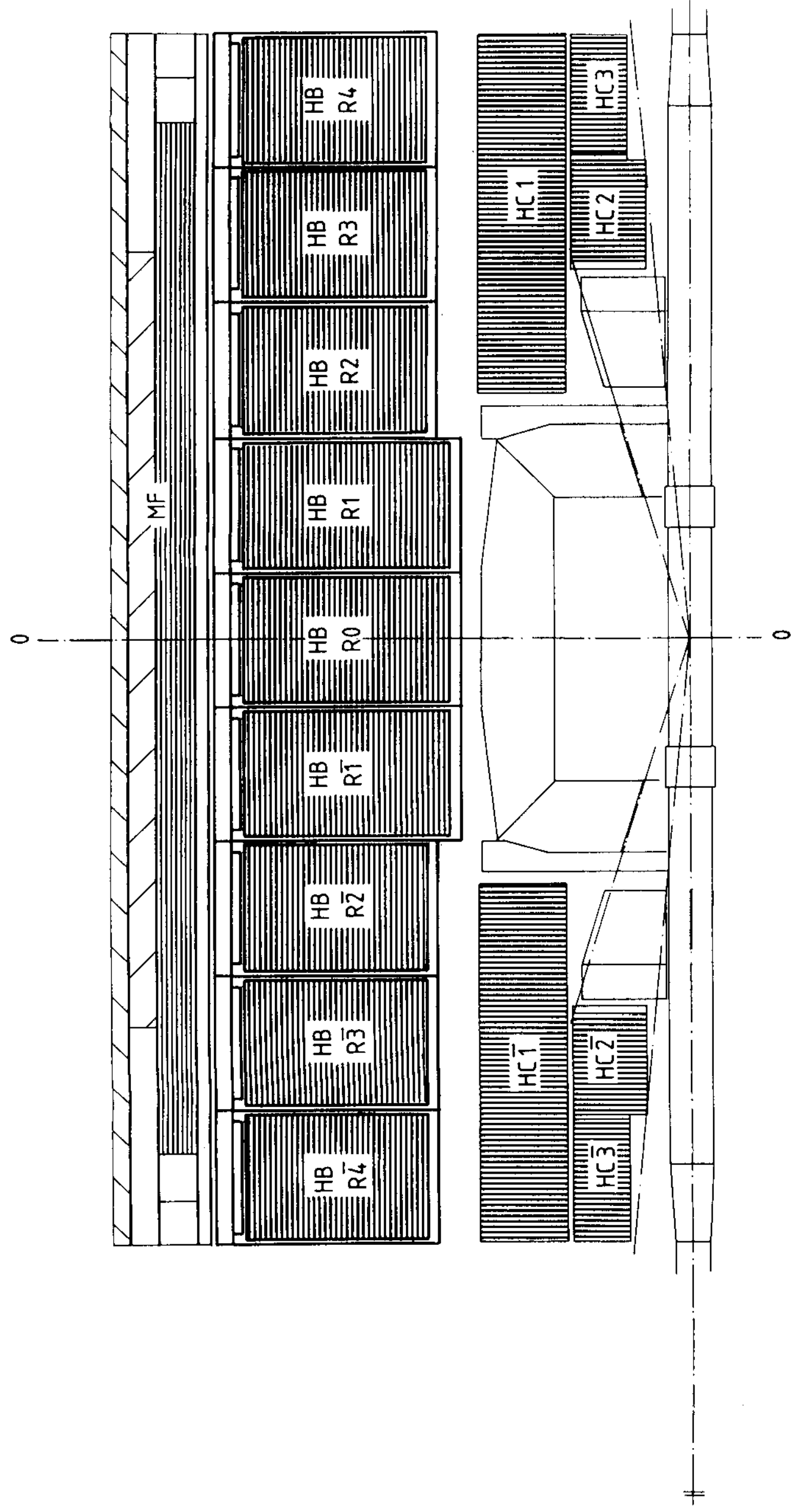

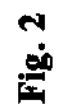




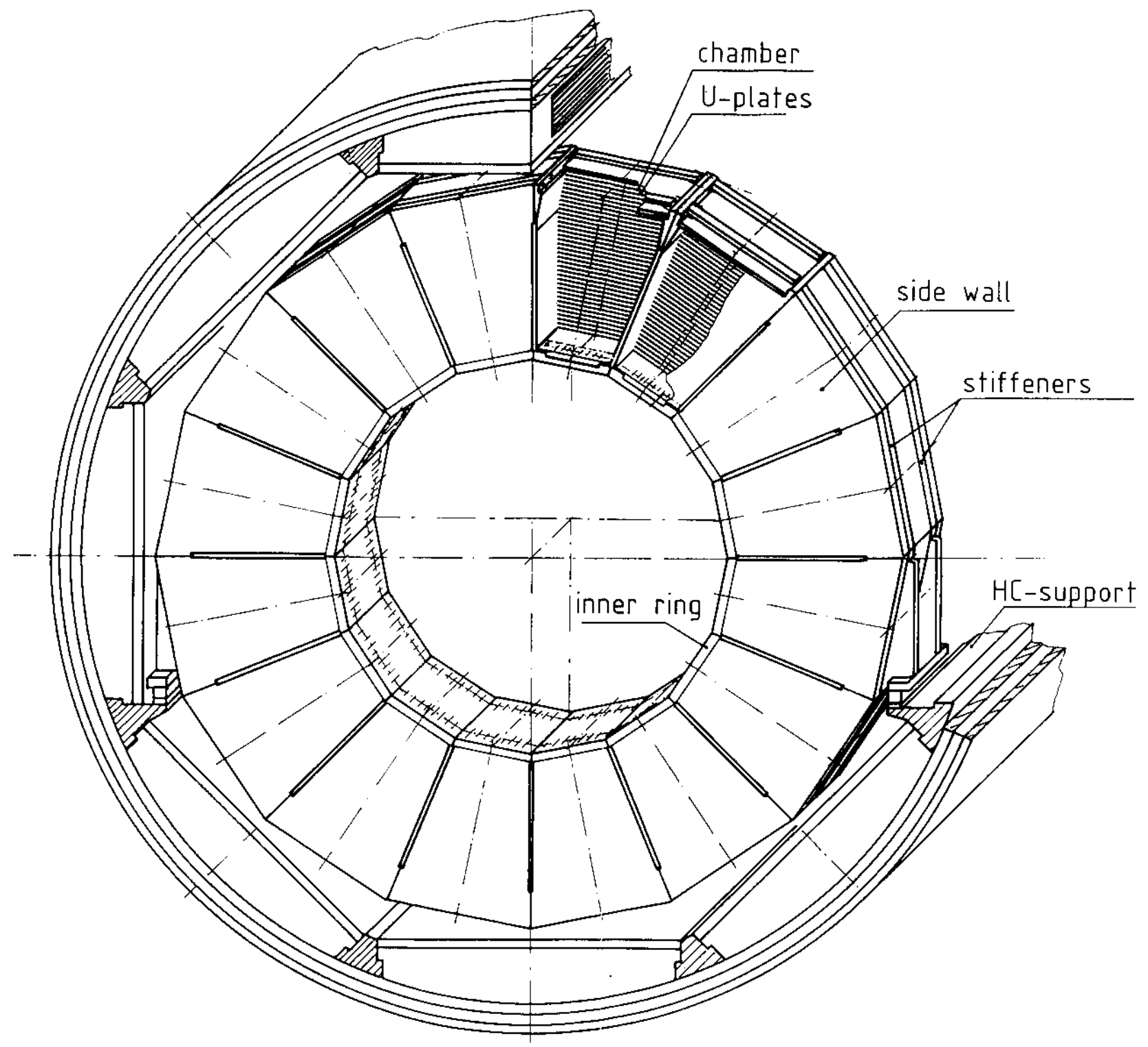

Fig. 3 


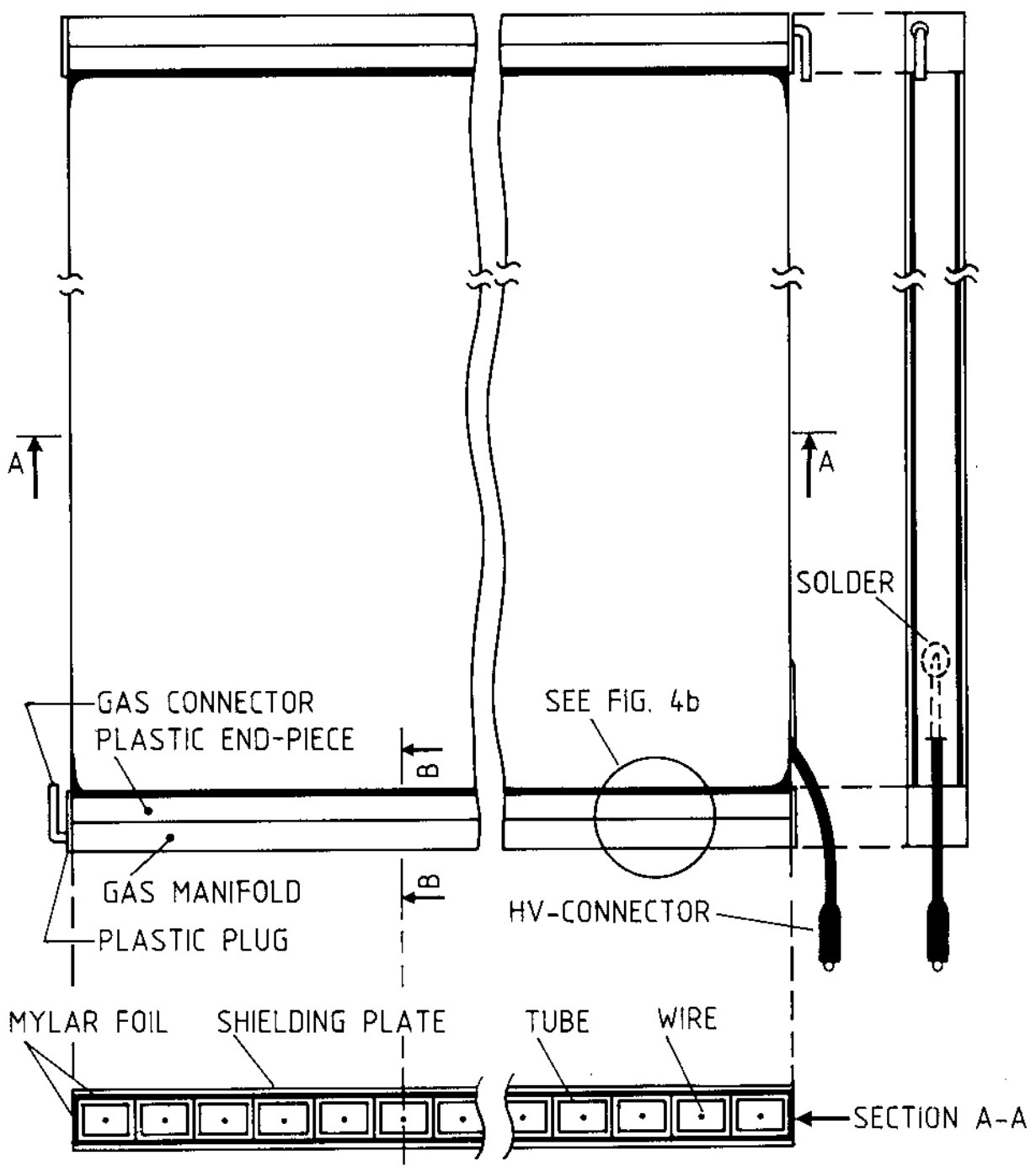

a)

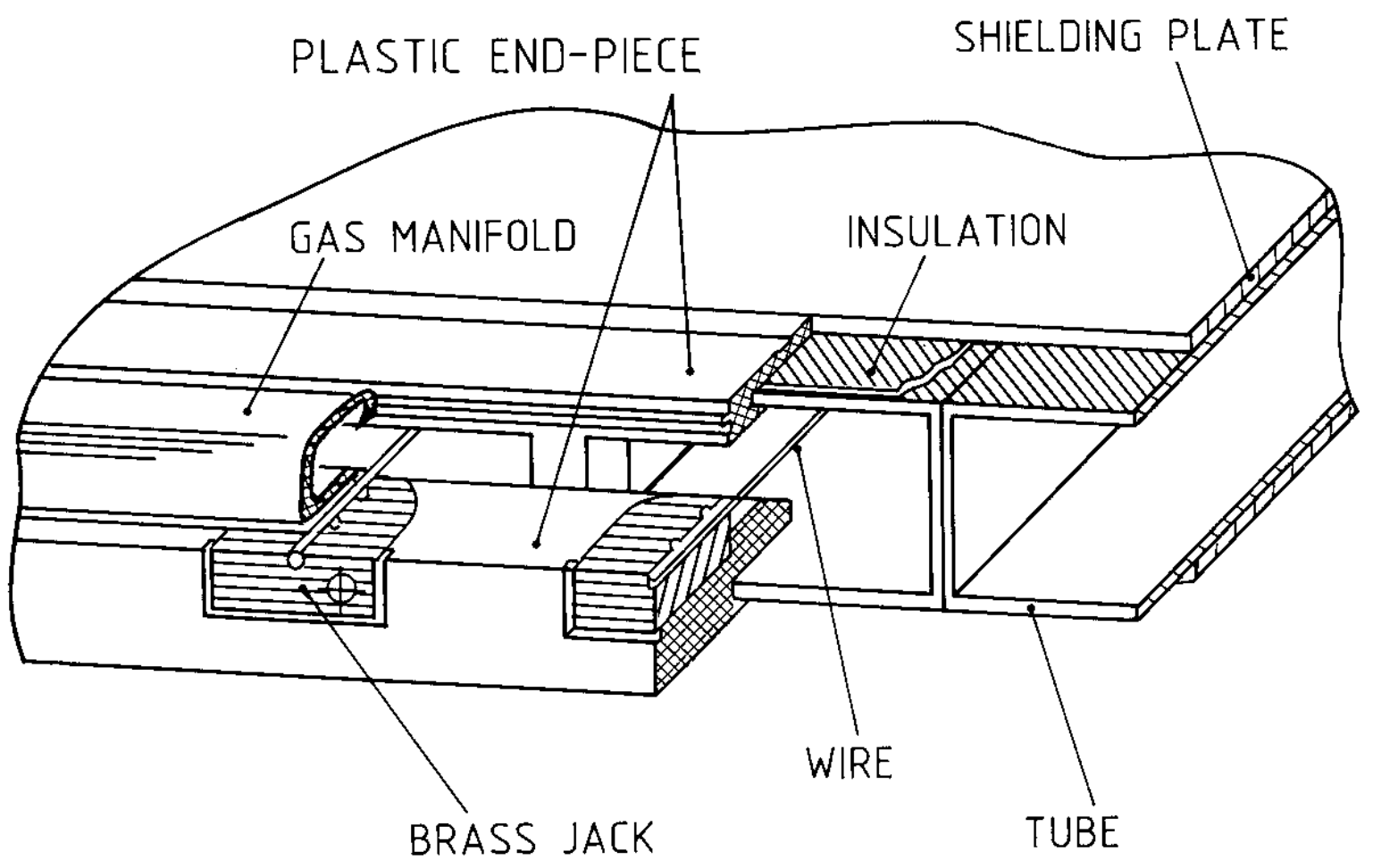

Fig. 4 


\section{SECTION B-B (SEE FIG. 4a)}

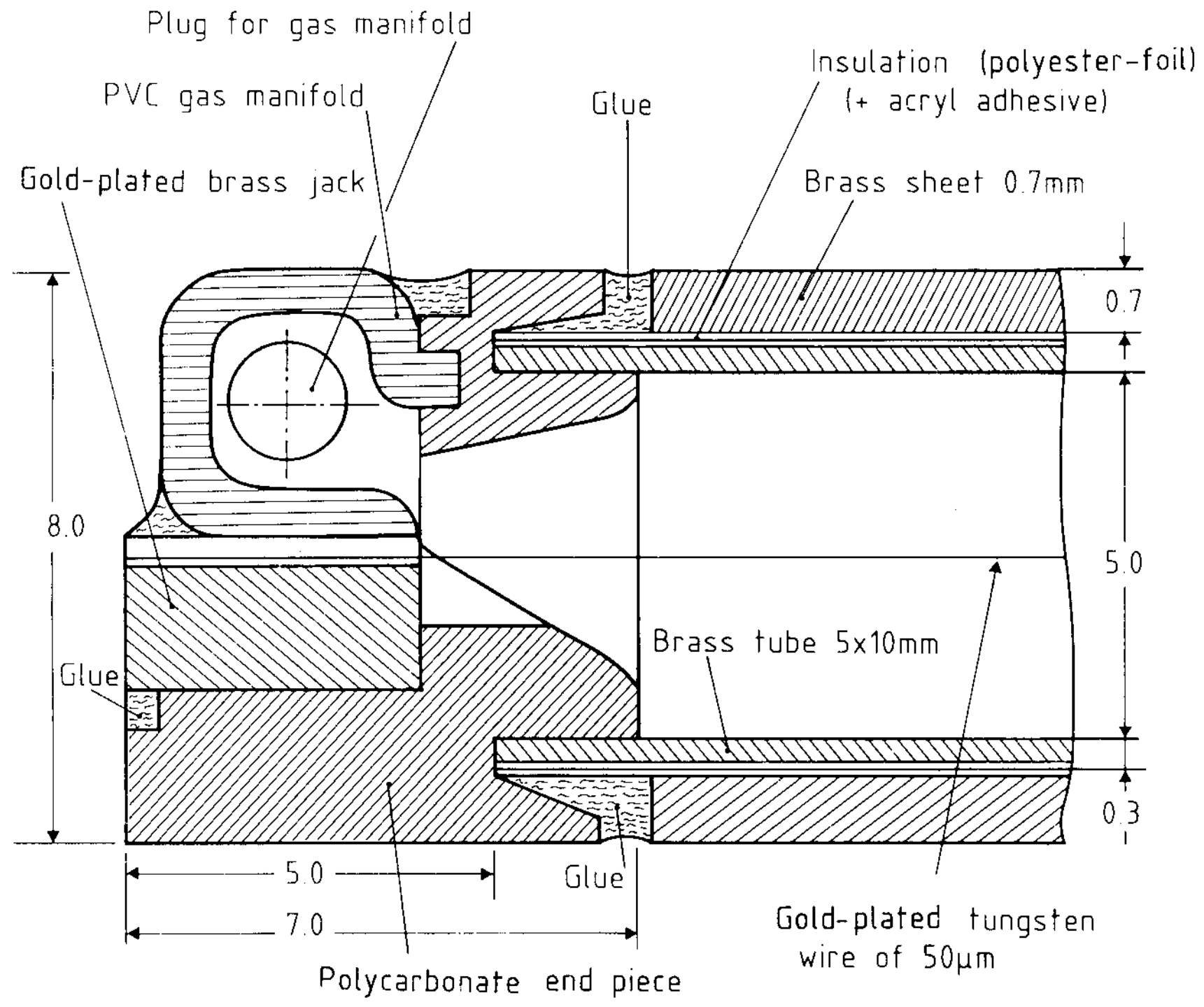

Fig. 5 


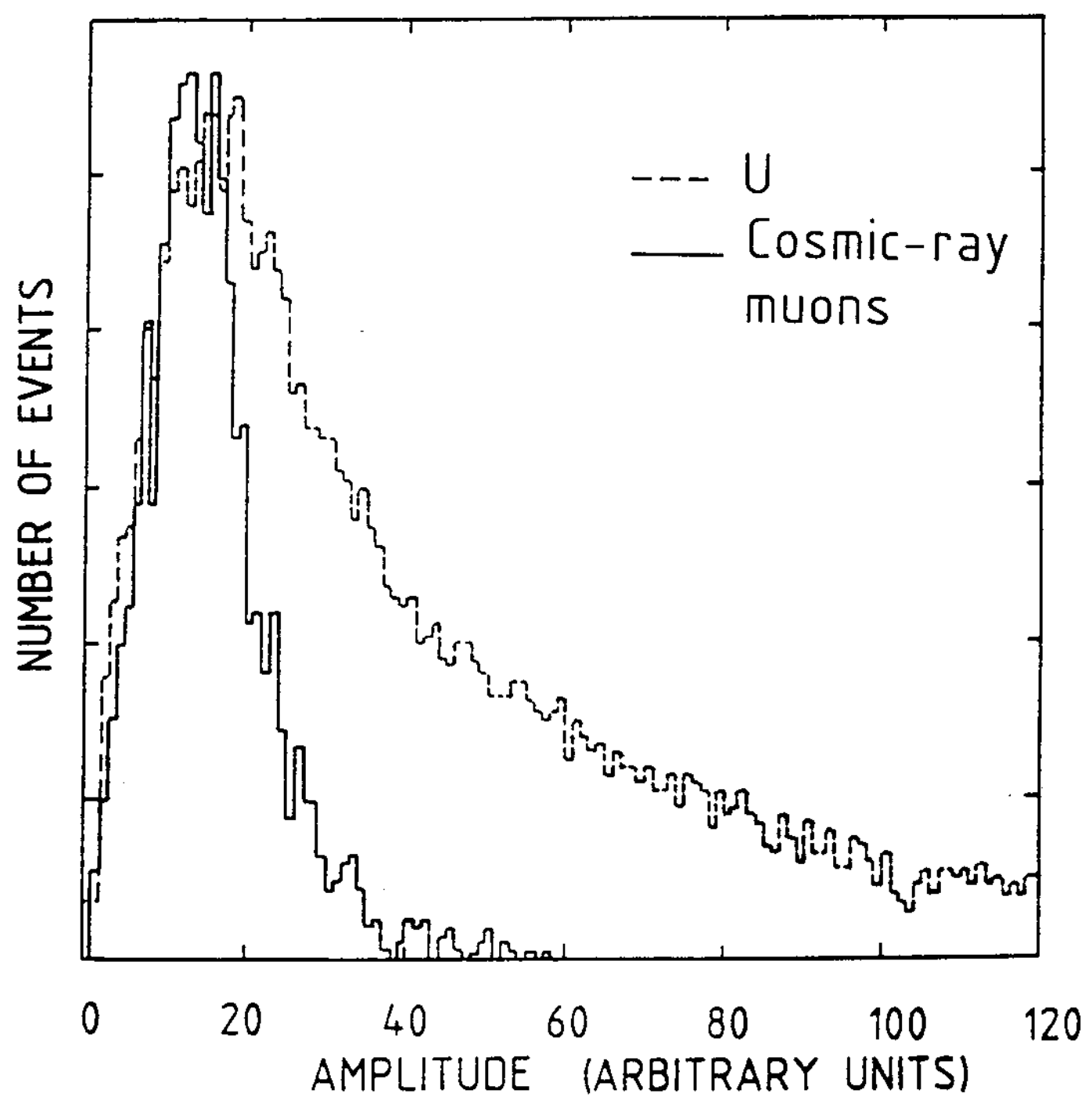

Fig. 6 


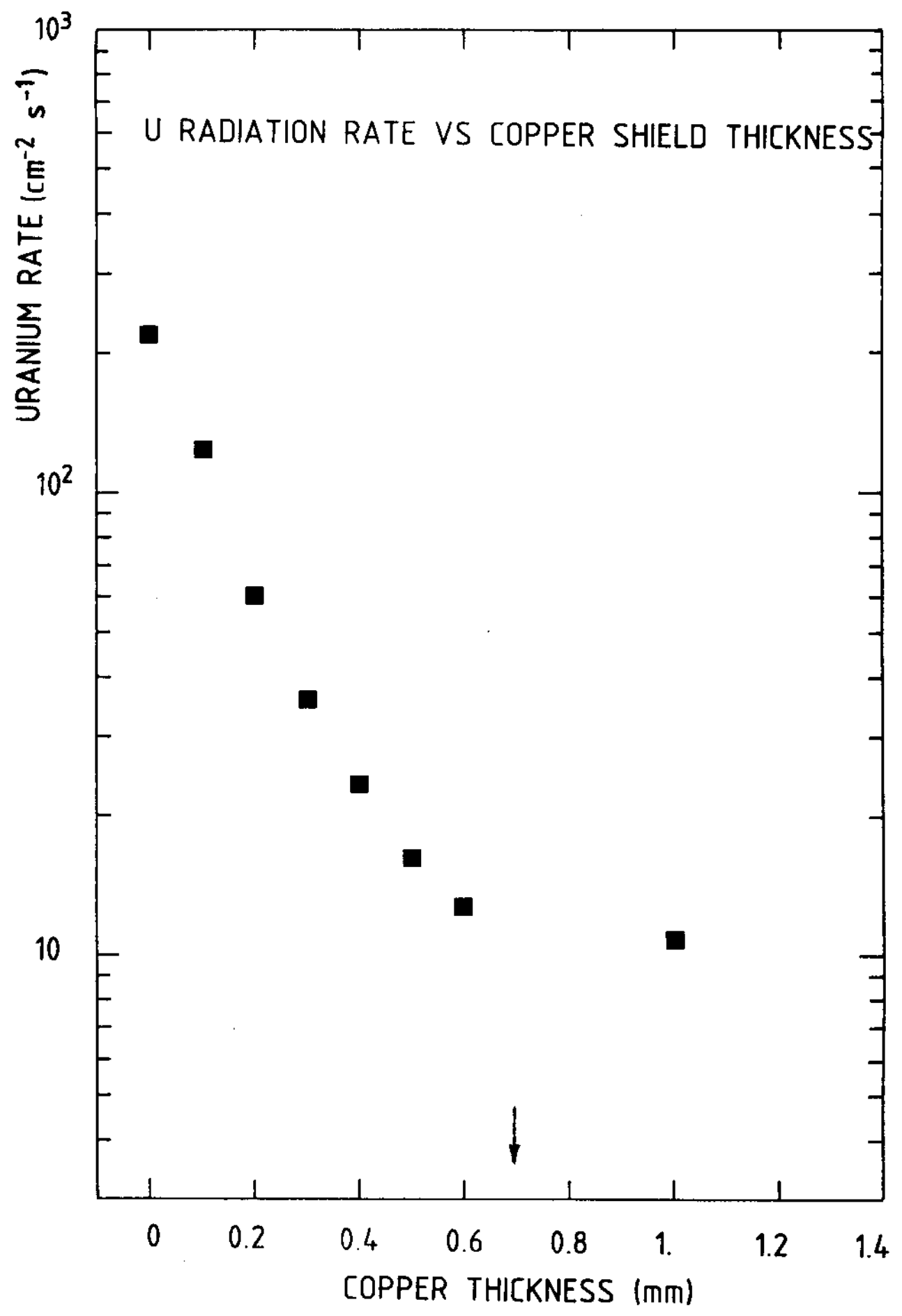

Fig. 7 


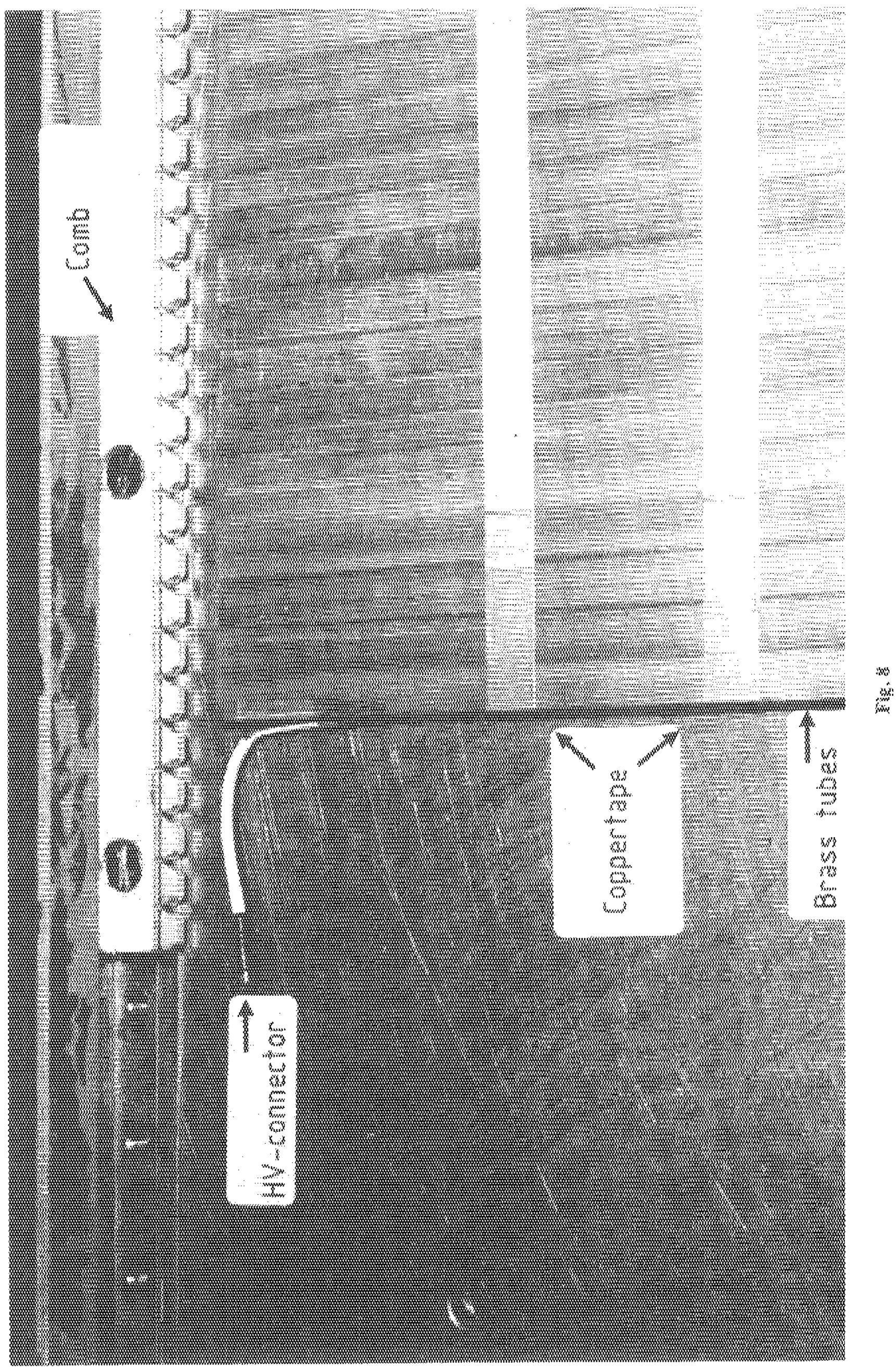




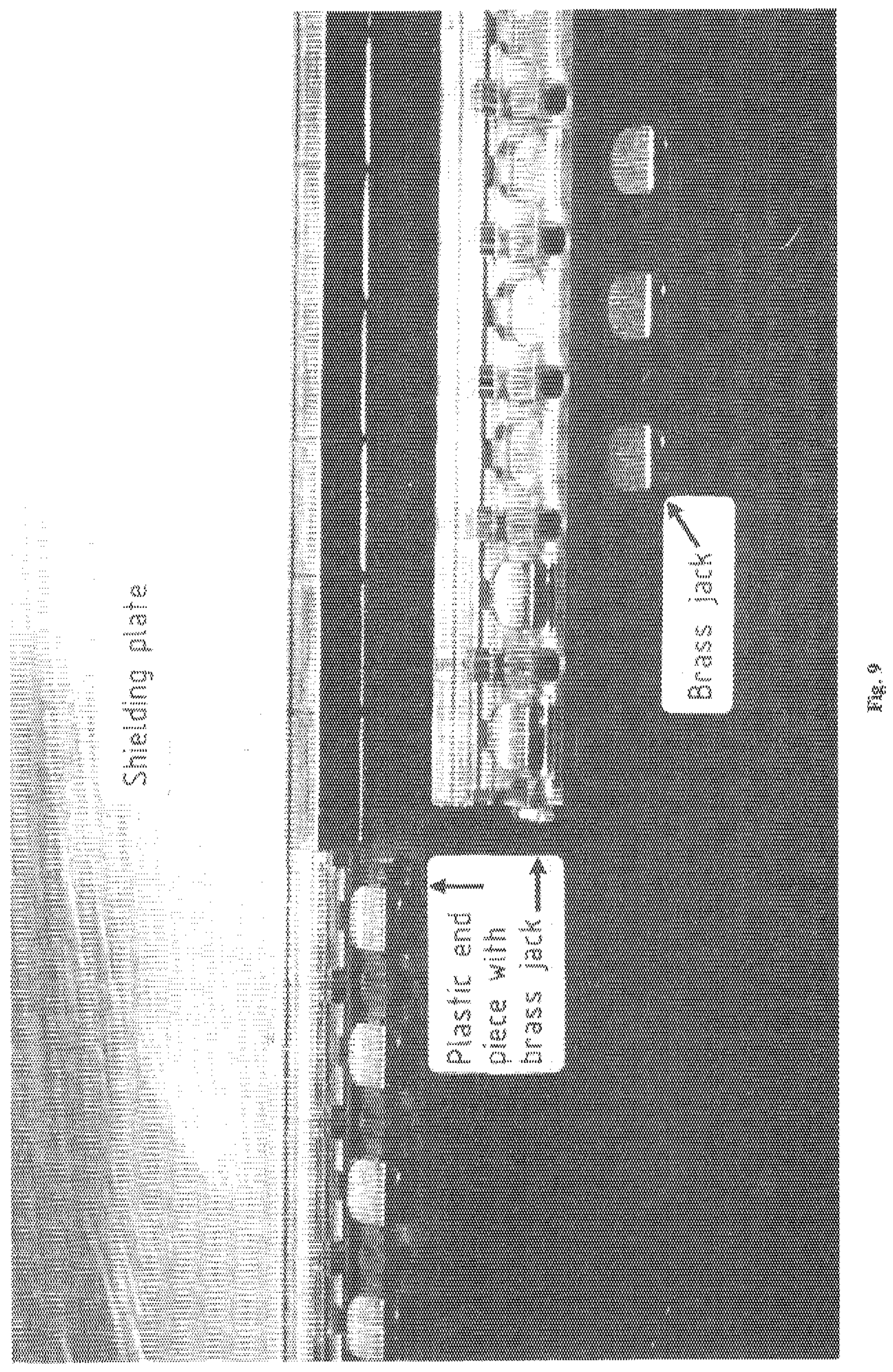




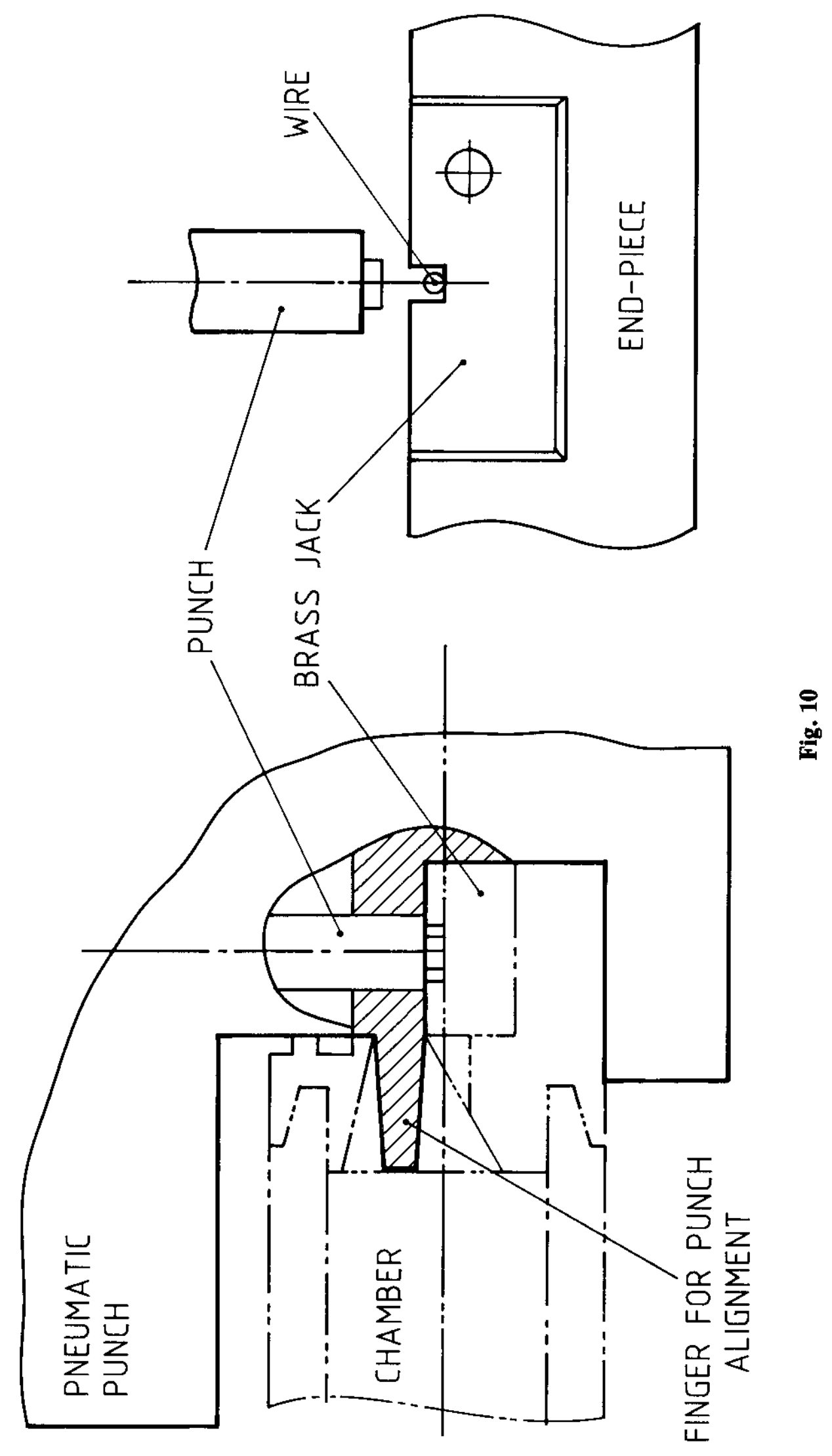




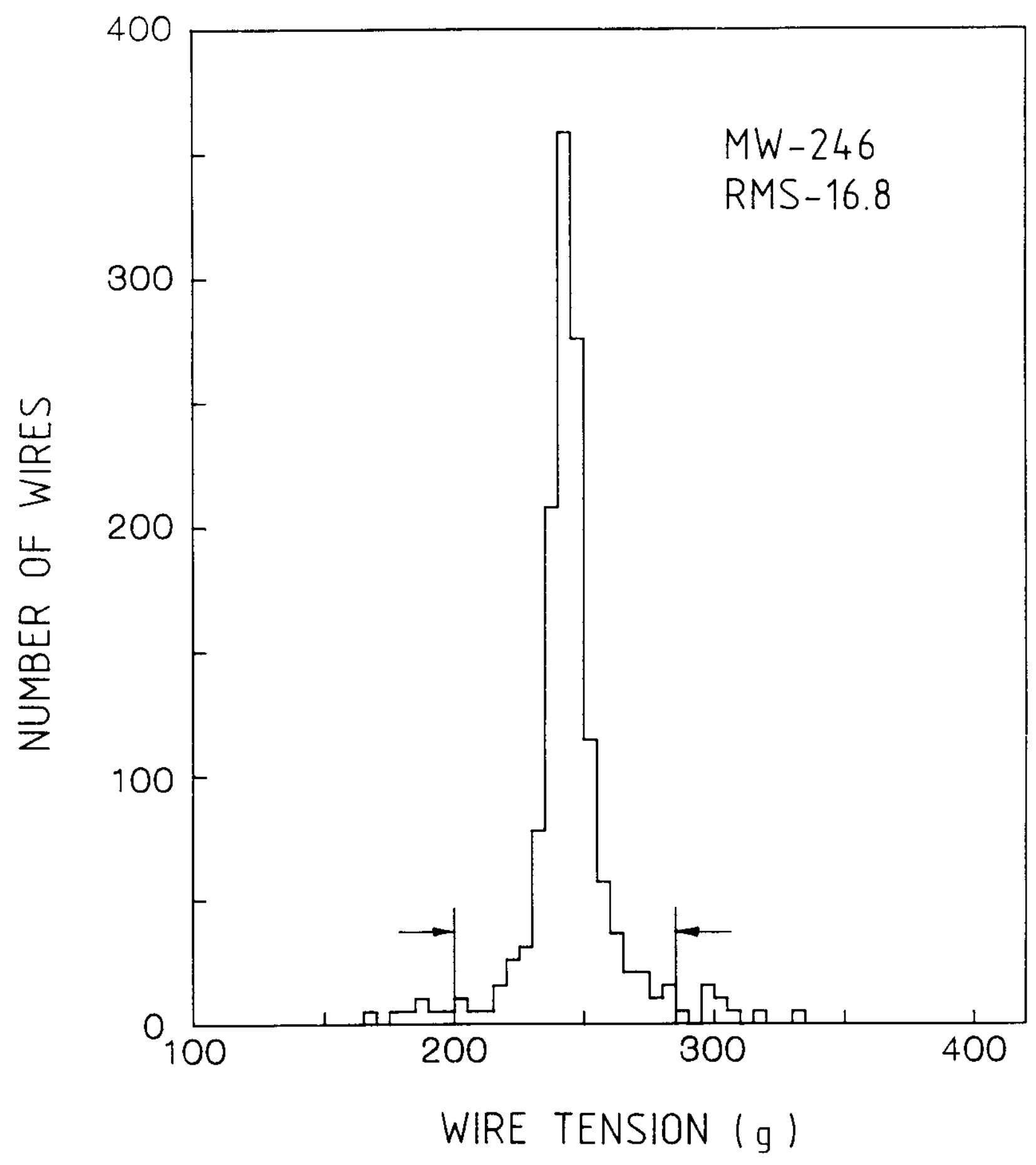

Fig. 11 


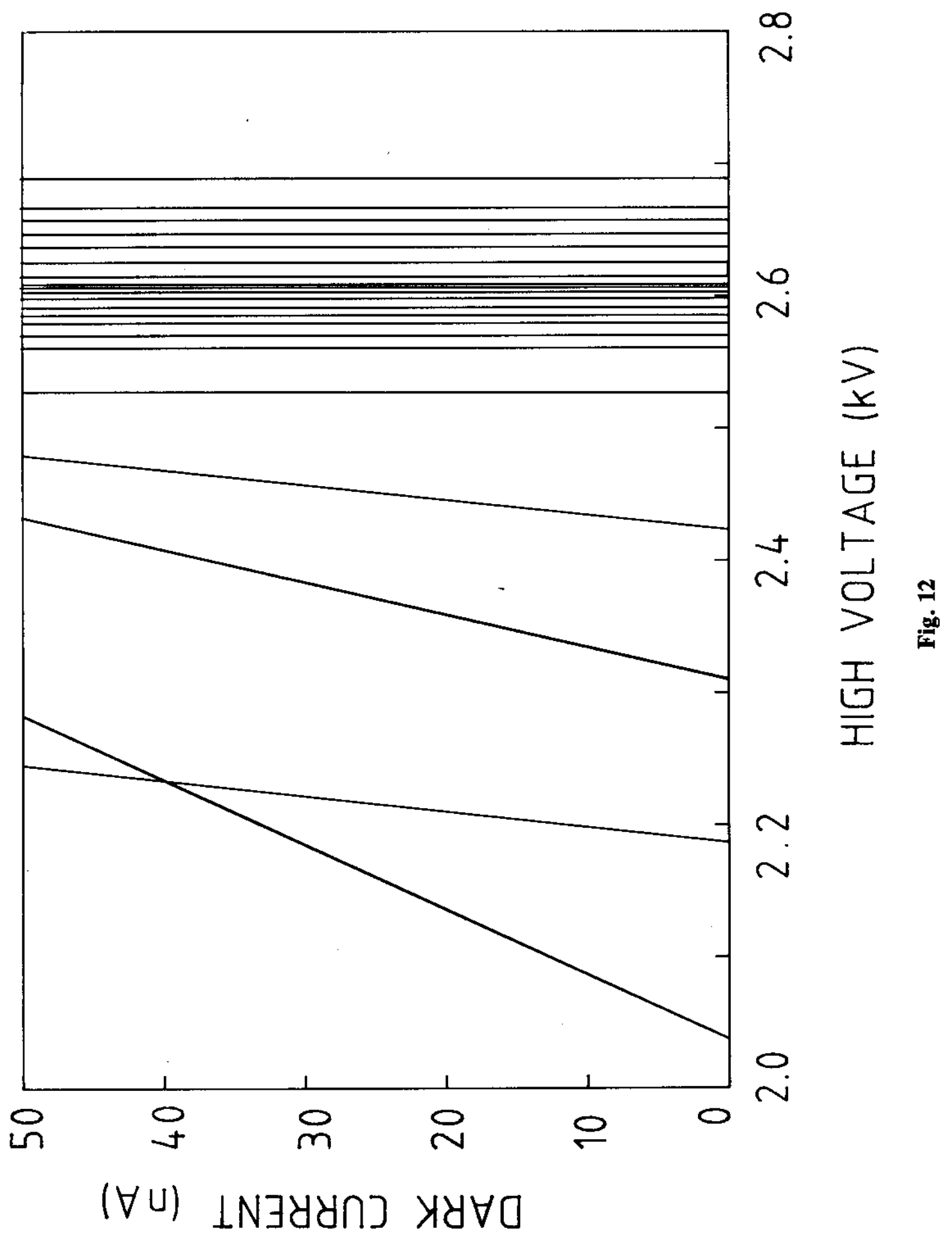




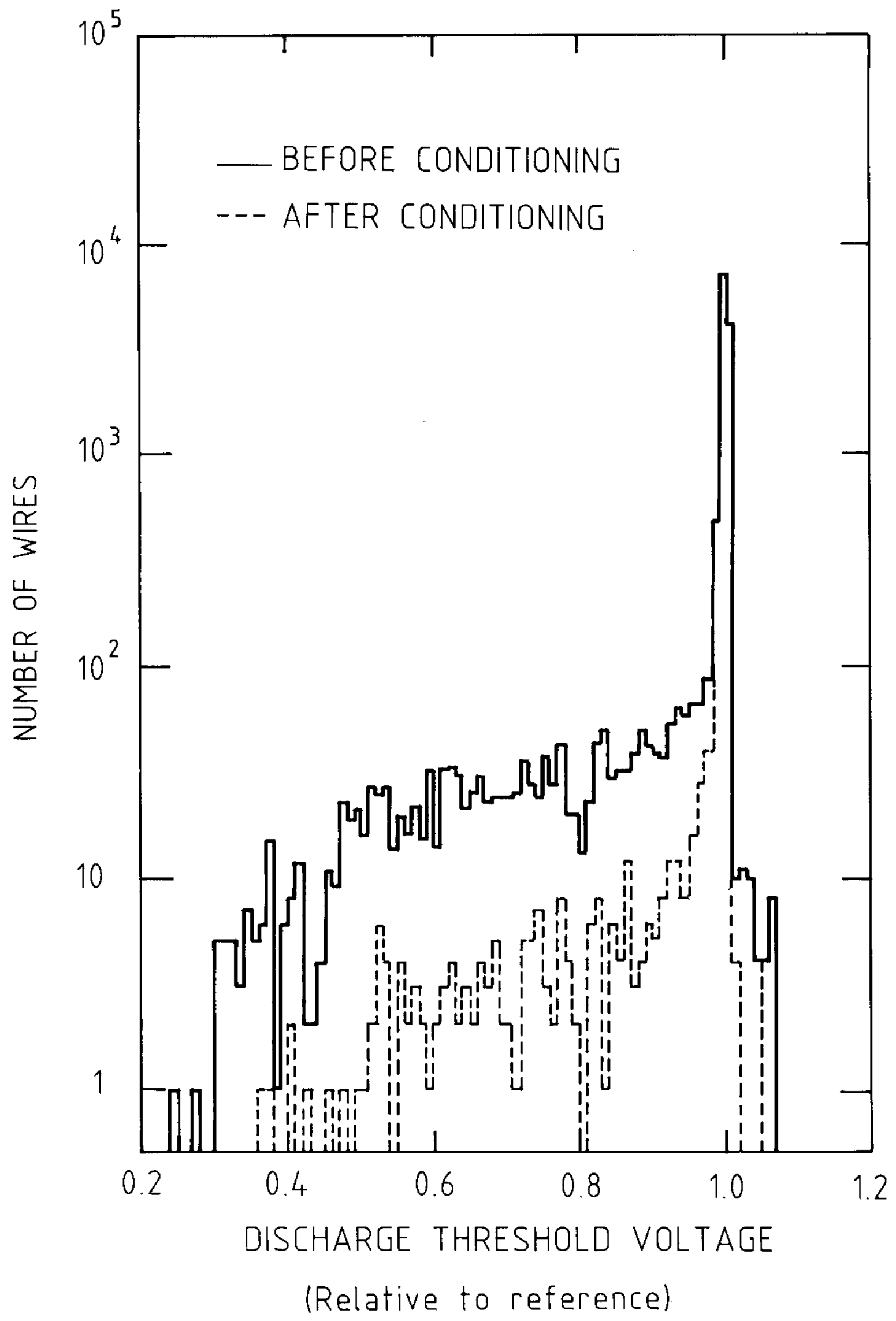

Fig. 13 


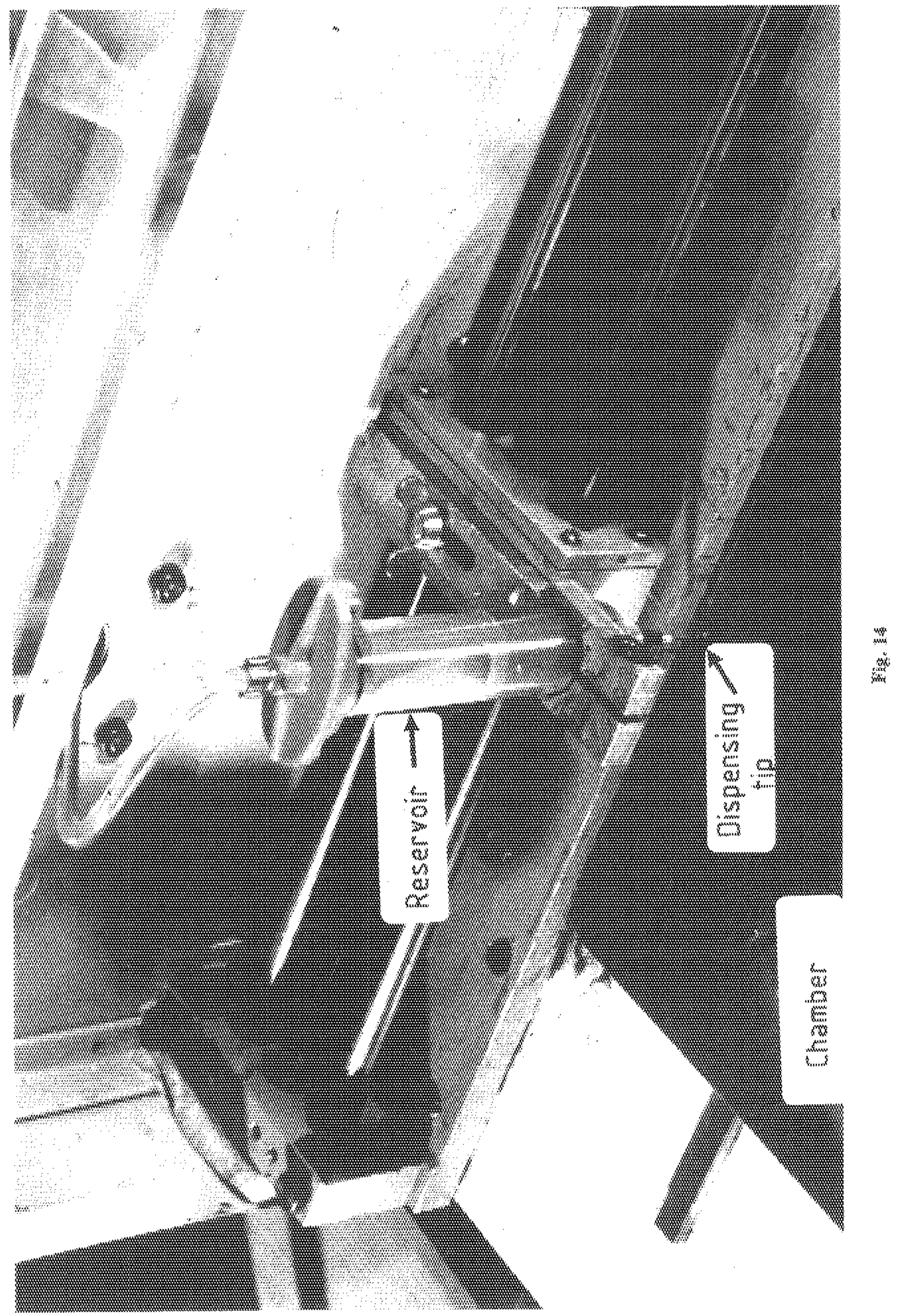




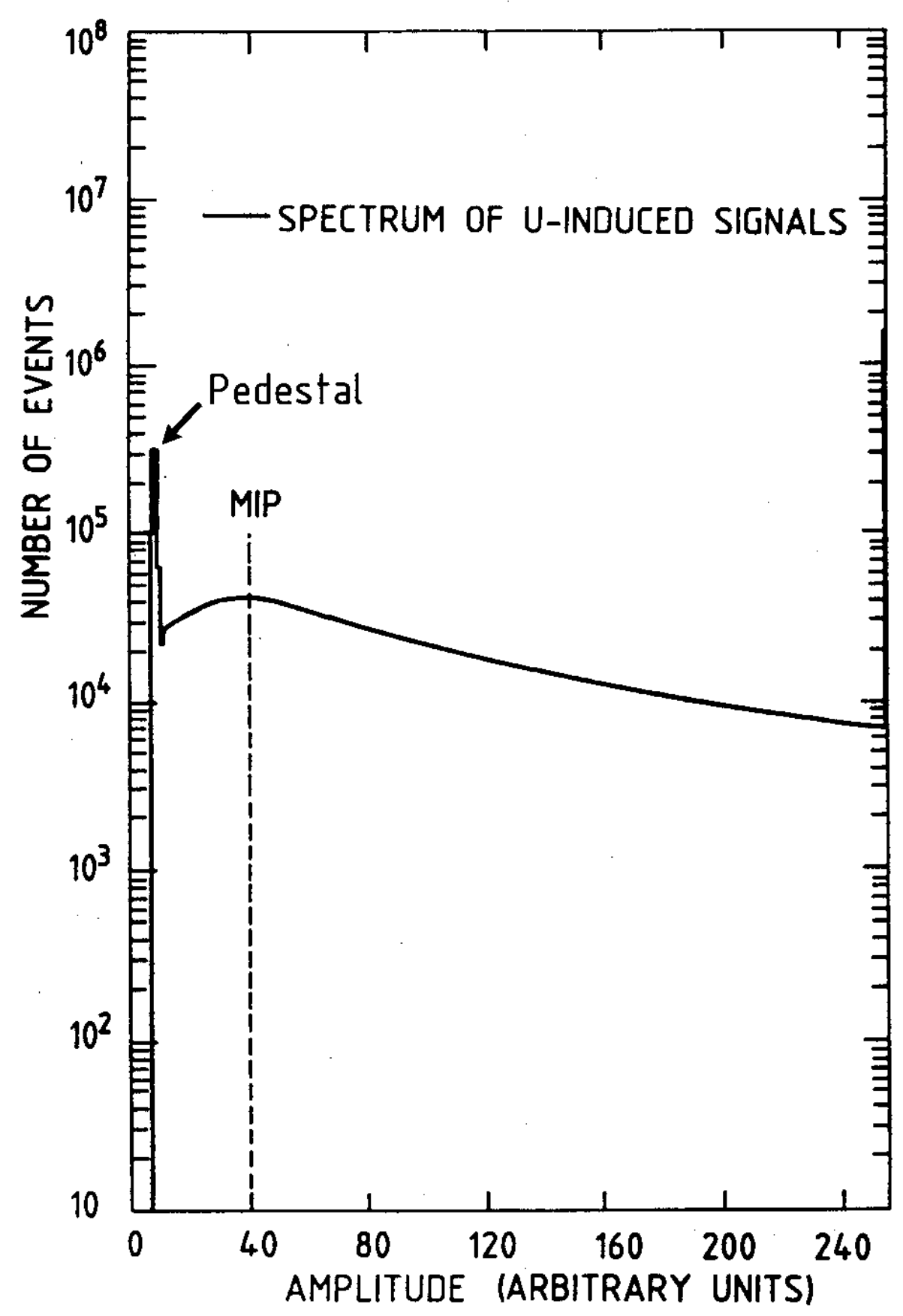

Fig. 15 


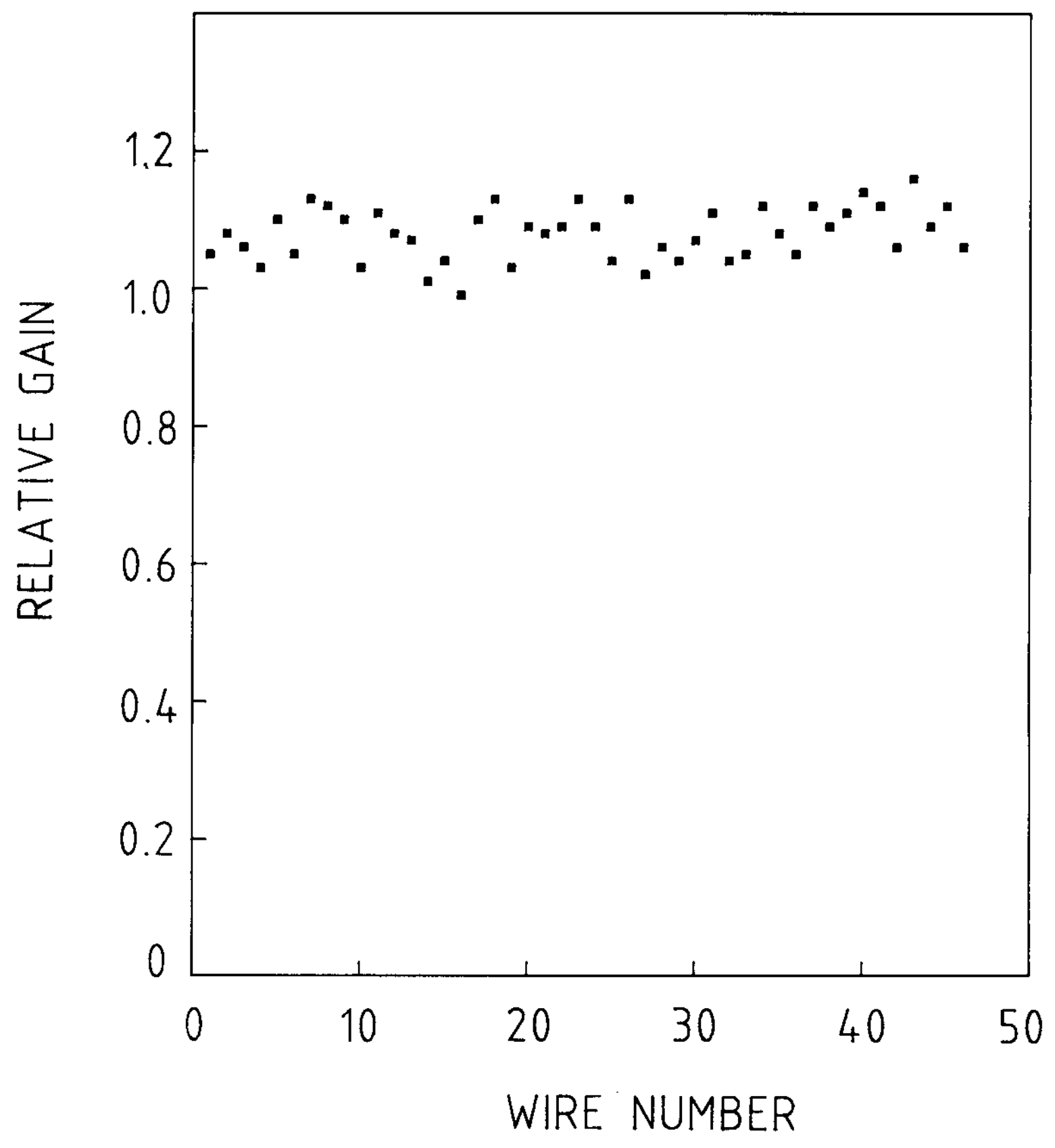

Fig. 16 


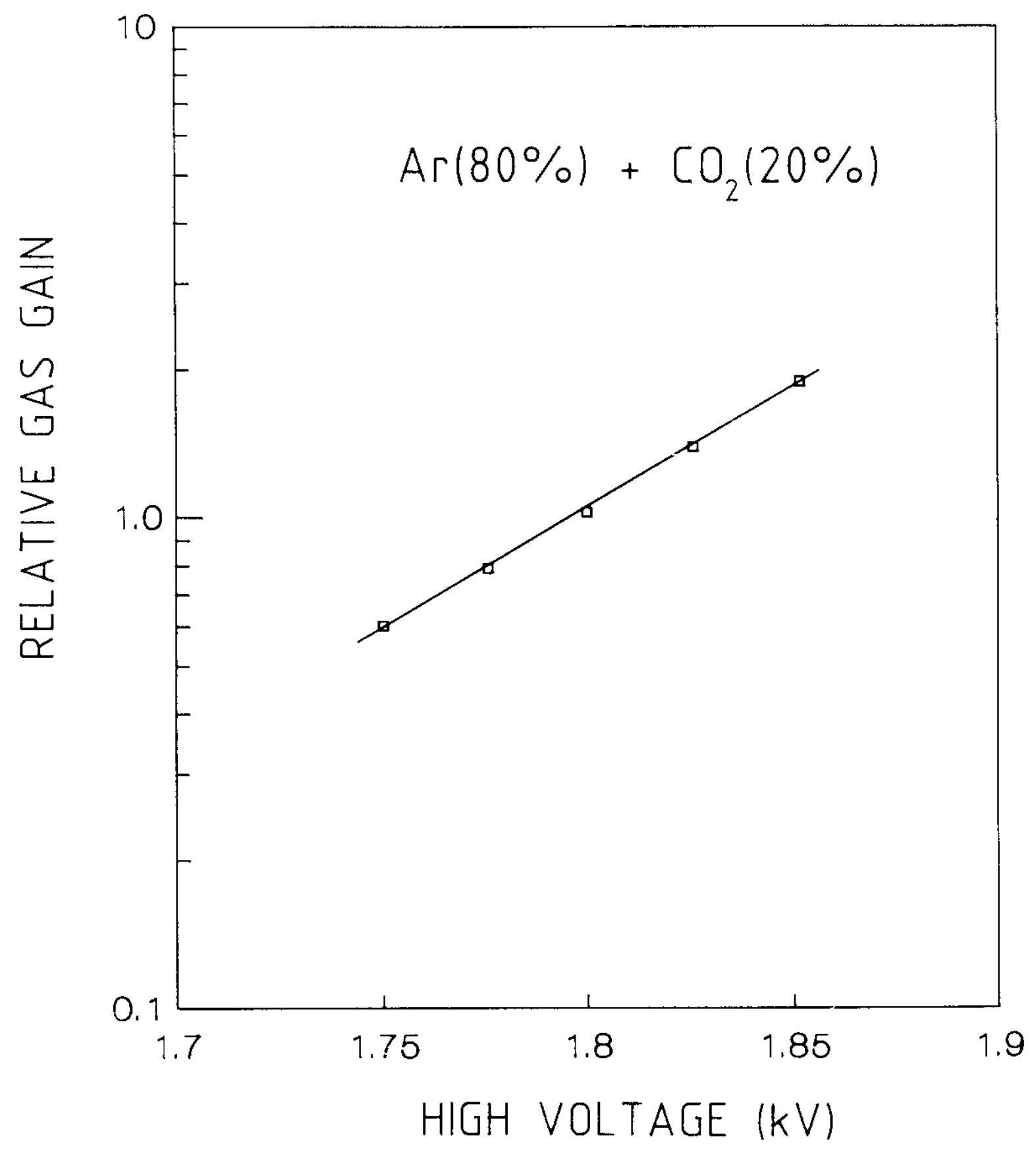

Fig. 17 


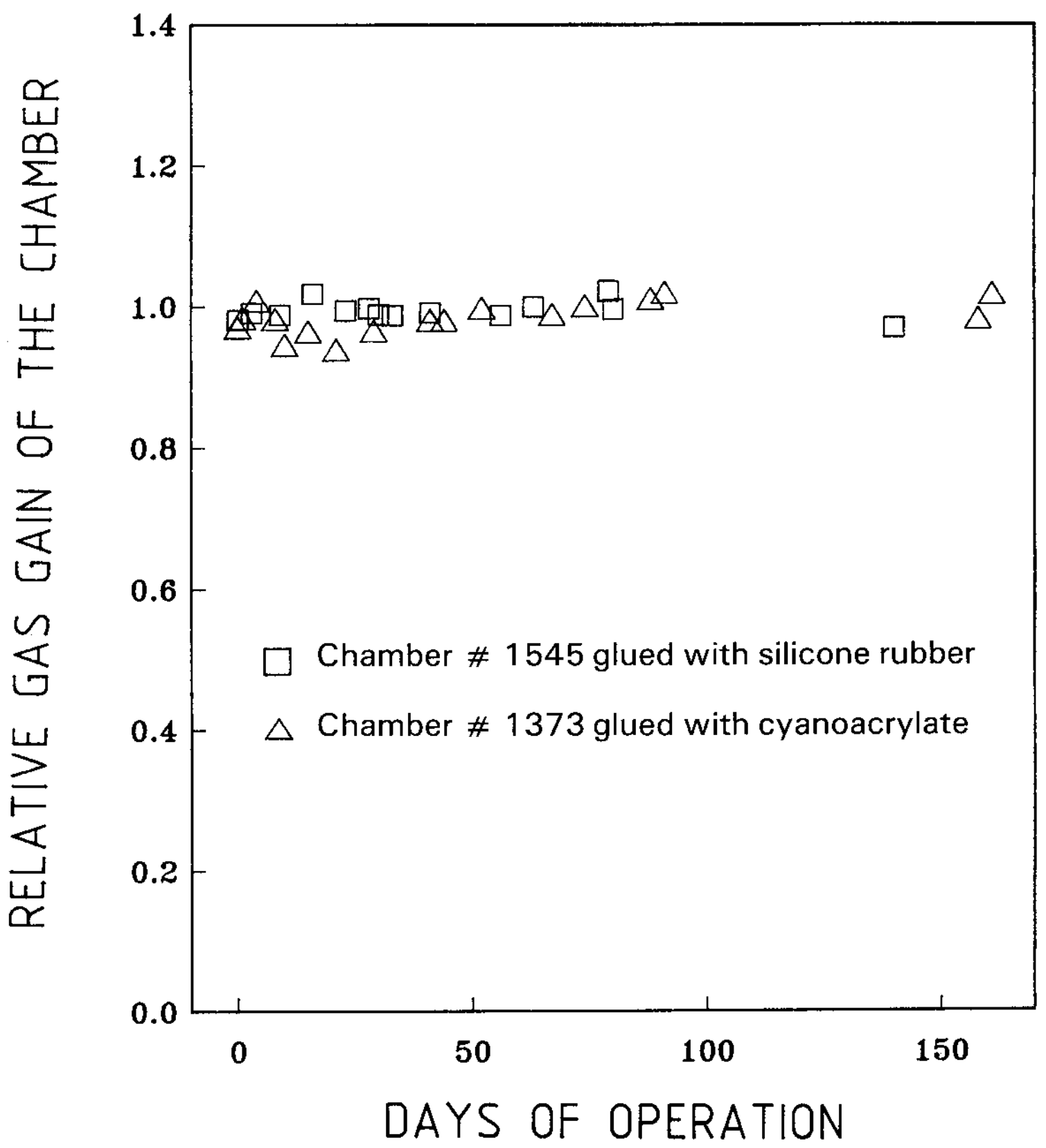

Fig. 18 


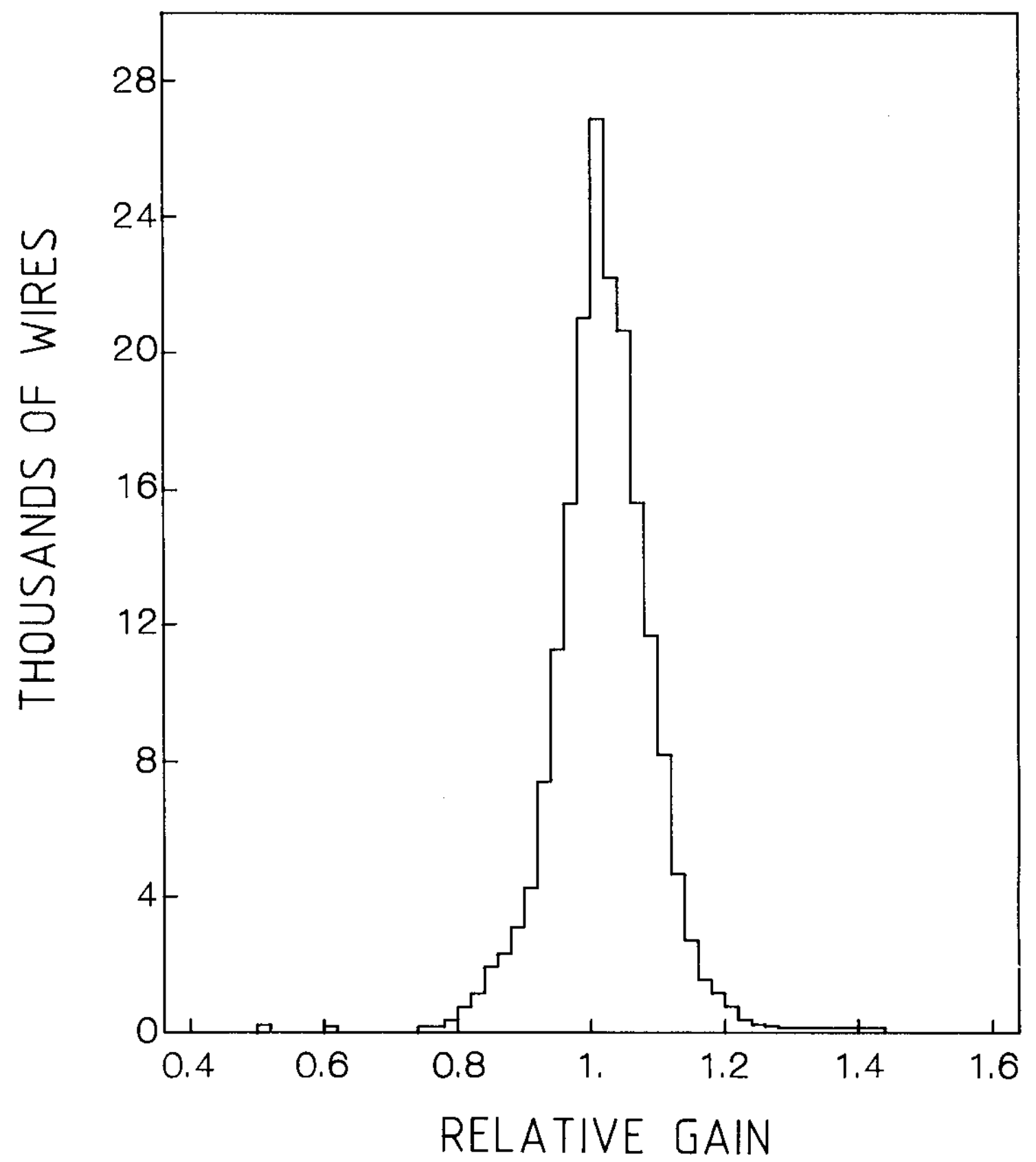

Fig. 19 